Leili Yekefallah', Mohammad Ali Zohal' ${ }^{2}, 0$ mmolbanin Keshavarzsarkar ${ }^{2}$, Ameneh Barikani², Maryam Gheraati ${ }^{2}$

'Faculty of Nursing \& Midwifery, Qazvin University of Medical Science Qazvin, Iran

${ }^{2}$ Oazvin University of Medical Science Qazvin, Iran

\title{
Comparing the effects of upper limb and breathing exercises on six-minute walking distance among patients with chronic obstructive pulmonary disease: a three-group randomized controlled clinical trial
}

\author{
The authors declare no financial disclosure
}

\section{Abstract}

Introduction: Physical exercise can improve patient outcomes and reduce hospitalization and mortality rates among subjects with chronic obstructive pulmonary disease. This study aimed to compare the effects of upper limb and breathing exercises on six-minute walking distance among these patients.

Material and methods: This three-group randomized controlled clinical trial was conducted in 2017-2018 in Velayat hospital, Qazvin, Iran. Seventy-five patients were purposively selected from the outpatient lung clinic of the hospital and randomly allocated to either the 25-patient groups of upper limb exercise, breathing exercise, or control. The patients in the first group were performing upper limb exercises thrice weekly for one month in the study setting. Their counterparts in the second group were doing pursed-lip and diaphragmatic breathing exercises four times daily for one month at their homes. However, the patients in the control group received no exercise intervention. Six-minute walk test was performed by each participant both before and after the study intervention. The SPSS for Windows program (v. 23.0) was used to analyze the data via the Chi-square test, the paired-sample $t$ test, and the one-way analysis of variance.

Results: Before the intervention, the groups did not significantly differ from each other respecting six-minute walking distance. During the study, walking distance in the control group did not change significantly, while it remarkably increased in both the upper limb exercise and the breathing exercise groups $(p<0.05)$. After the intervention, walking distance in the upper limb exercise group was significantly greater than the breathing exercise group $(p<0.05)$ and the control group $(p<0.05)$; however, the difference between the breathing exercise and the control groups was not statistically significant $(p>0.05)$.

Conclusion: Upper limb exercise is more effective than breathing exercise in increasing walking distance among patients with chronic obstructive pulmonary disease. Therefore, upper limb exercise can be used as a safe, simple, and inexpensive rehabilitation technique for these patients.

Key words: chronic obstructive pulmonary disease, upper limb exercise, breathing exercise, six-minute walk test

Adv Respir Med. 2019; 87: 77-82

\section{Introduction}

Chronic obstructive pulmonary disease (COPD) is a respiratory disorder which is associated with an ongoing limitation of airflow [1].
The underlying cause of COPD is a chronic inflammation in the lung and airways in response to poisonous particles and gases [2]. During physical activity, COPD-associated limitation in the airflow is exacerbated and the resultant dyspnea prevents

Address for correspondence: Mohammad Ali Zohal, Qazvin University of Medical Science Qazvin, Iran, e-mail: Mzohal@qums.ac.ir

DOI: 10.5603/ARM.2019.0013

Received: 26.11.2018

Copyright (C) 2019 PTChP

ISSN 2451-4934 
patients from continuing physical activity [3]. Known factors in the pathophysiology of COPD include environmental and genetic factors and cigarette smoking $[4,5]$. COPD has a high prevalence of $14-17 \%$ [2].

COPD is associated with different negative outcomes such as activity limitation, infections, huge costs, disability, and death [6]. According to the World Health Organization, COPD will be the third leading cause of death by 2030 [7]. Estimates also show that 1.5 million of all annual emergency department admissions are related to COPD and around 700,000 patients with COPD are hospitalized each year [8]. Moreover, in the European Union countries, around 6\% of the total health budget of the Union is spent on the direct costs of COPD management. Besides its direct costs, COPD has huge indirect costs related to its negative effects on patients' physical, occupational, and social functioning [9].

Limitation of physical activity is one of the major consequences of COPD. Afflicted patients have limited functional capacity and experience dyspnea and fatigue during daily activities $[10,11]$. Dyspnea, in turn, is a major cause of disability, fatigue, and physical activity limitation [12]. Consequently, patients with COPD need to reduce their activities of daily living (such as bathing, driving, cooking, and exercising) in order to prevent or minimize dyspnea and fatigue $[13,14]$. Besides dyspnea and fatigue, limitation of physical activity among patients with COPD is caused by COPD-associated muscular problems because COPD has negative effects on muscles and causes muscular atrophy, weakness, and fatigue [15], particularly in the upper limbs [11]. Such muscular problems further limit patients' ability to perform physical activity. COPD-associated muscular problems reduce the quality of life, increase patients' use of healthcare services, and elevate mortality rate [16].

Given the significant role of respiratory and muscular problems in reducing physical functioning among patients with COPD, physical and breathing exercises may help improve their physical functioning. Studies have shown that exercise can positively affect functional capacity and reduce disability, hospitalization, morbidity, and mortality among these patients $[17,18]$. Thus, promoting patients' engagement in physical and breathing exercises is among the major priorities in COPD management [19]. A study reported that increases in the level of physical exercise among patients with COPD are associated with improvements in the ability to perform physical activity and reductions in hospitalization and mortality rates [20].

Despite the potential advantages of physical exercise to patients with COPD, few studies had assessed the effects of upper limb exercise on COPD-related outcomes. Most studies in this area had been on the results of lower limb exercises $[21,22]$. To fill this gap, the present study was conducted to compare the effects of upper limb and breathing exercises on six-minute walking distance among patients with COPD.

\section{Material and methods}

This three-group randomized controlled clinical trial was conducted in 2017-2018.

The study population comprised all patients with COPD who referred to the outpatient lung clinic of Velayat teaching hospital, Qazvin, Iran. Based on the findings of an earlier study [23].

Sample size with $\alpha=0.05$ and $\beta=0.2$, and the mean of $\mathrm{FEV}_{1}$ in the control group (34.67 \pm 13.7)and in the Aerobic group ( $51 \pm 5.97)$ was calculated as follows:

$$
n=\frac{\left(z_{1-\alpha / 2}+z_{1-\beta}\right)^{2}\left(\sigma_{1}^{2}+\sigma_{2}^{2}\right)}{\left(\mu_{2}-\mu_{1}\right)^{2}}=\frac{(1.96+0.84)^{2}\left(13.7^{2}+18.97^{2}\right)}{(51-34.67)^{2}} \sim 17
$$

Seventeen people in each group were estimated, but with considering the $10 \%$ of missing, 25 people in each group were enrolled in the study.

Accordingly, 75 patients with severe to moderate COPD (as determined basing on the GOLD system for COPD classification) were purposively selected. Selection criteria were an age of 30-90, a definite diagnosis of COPD by a pulmonologist, and stable physiological and hemodynamic conditions. The patients were excluded if they experienced symptom exacerbation, developed serious cardiopulmonary or neuromuscular problems which interfered with performing exercises, failed to complete exercise checklist, and did not refer to the study setting for doing exercises based on the predetermined schedule. Through block randomization, selected patients were randomly allocated to either an upper limb exercise $(\mathrm{n}=25)$, a breathing exercise $(n=25)$, or a control group $(n=25)$. Accordingly, triple blocks were generated out of the upper limb exercise (A), breathing exercise (B), or control (C) groups as the following: $A B C$, ACB, BAC, BCA, CAB, and CBA. Then, for each three patients, one block was randomly selected using a random number table and then, the subjects were allocated to the groups based on the selected block. 
Initially, all selected patients were invited to attend an instructional session about the study, during which they were informed about the study aim and were asked to read and sign the informed consent for participation. Then, data on the demographic characteristics of the patients who consented for participation were collected and they underwent the six-minute walk test. After that, the study intervention started.

While the patients in the control group received no exercise intervention, the study intervention for the subjects in the upper limb exercise group consisted of strengthening exercises thrice weekly for one month - twelve thirty-minute sessions in total. All sessions were held by the second author in the cardiopulmonary rehabilitation center of Velayat hospital. In each session, the patients' vital signs and arterial oxygen saturation were monitored and then, they sat on chairs to perform light upper limb warm-up exercises for five minutes, light upper limb strengthening exercises using one- or two-kilogram dumbbells for twenty minutes, and cool-down exercises for five minutes. Initially, the participants watched each strengthening exercise done by the first author and then, they did it ten to twelve times with 2-3 minute rest intervals during the exercises. The patients were allowed to repeat the exercises according to their preferences and abilities. Finally, their vital signs and arterial oxygen saturation were re-monitored at the end of each session.

The intervention for the patients in the breathing exercise group consisted of pursed-lip and diaphragmatic breathing. These exercises were taught to patients by the second author in three one-hour personal face-to-face sessions held on three successive days in the cardiopulmonary rehabilitation center of Velayat hospital. Then, they were asked to do these exercises four times daily (morning, noon, evening, and night) for one whole month. The patients were taught to do each breathing exercise for one minute and consider a one-minute rest between each two exercise. Moreover, they were provided with an exercise checklist and were asked to complete it after each session of breathing exercise. Each evening throughout the study, the second author telephoned patients in this group to remind them of doing the breathing exercises.

Data collection tool was a demographic and clinical characteristics questionnaire which contained items on participants' age, gender, marital status, educational status, employment status, COPD duration, cigarette smoking, and COPD medications. Moreover, through the six-minute walk test performed according to the American Thoracic Society guideline, the patients' physical exercise ability was assessed. Accordingly, before the test, the intended patient was provided with detailed information about the test and was asked to wear a pair of walking shoes and comfortable clothes. Then, a portable pulse oximeter (CMS501) was attached to his/her wrist, baseline oxygen saturation and heart rate were monitored, and he/she was asked to walk as many times as possible on a thirty-meter line up to six minutes. The line had been marked every three meters to facilitate distance measurement. There were several chairs across the line on which the patient could sit and rest during the test. Finally, the total length every person walked was measured and documented in the six-minute walk test checklist. Besides the length item, this checklist contained items such as age, gender, height, weight, and pretest and posttest heart rate and oxygen saturation.

The SPSS for Windows program (v. 23.0) was used to analyze the data. The measures of descriptive statistics (i.e. mean, standard deviation, frequency, and percentage) were used for data description. Moreover, the Chi-square test and the one-way analysis of variance were conducted for group comparisons in terms of gender, marital, educational, and employment status, cigarette smoking, age, COPD duration, body mass index, and pretest and posttest walking distances. In addition, within-group comparisons in terms of walking distance were made through the paired-sample $t$ test. All statistical analyses were performed at a significance level of less than 0.05.

This study was registered in the Iranian Registry of Clinical Trials (registration number: IRCT20171006036584N1) and approved by the Ethics Committee of Qazvin University of Medical Sciences, Qazvin, Iran (approval code: IR.QUMS. REC.1365.293). The participants were informed about the study aim and ensured of the confidential handling of their information.

\section{Results}

All of the 75 included patients completed the study (Fig. 1). The study participants characteristics has been shown in Table 1. Most subjects were male (73.3\%), married (98.8\%), and retired $(57.3 \%)$, and more than one third of them had elementary education (34.7\%). The three groups of the study participants did not significantly differ from each other respecting their age, COPD duration, body mass index, gender, marital, edu- 


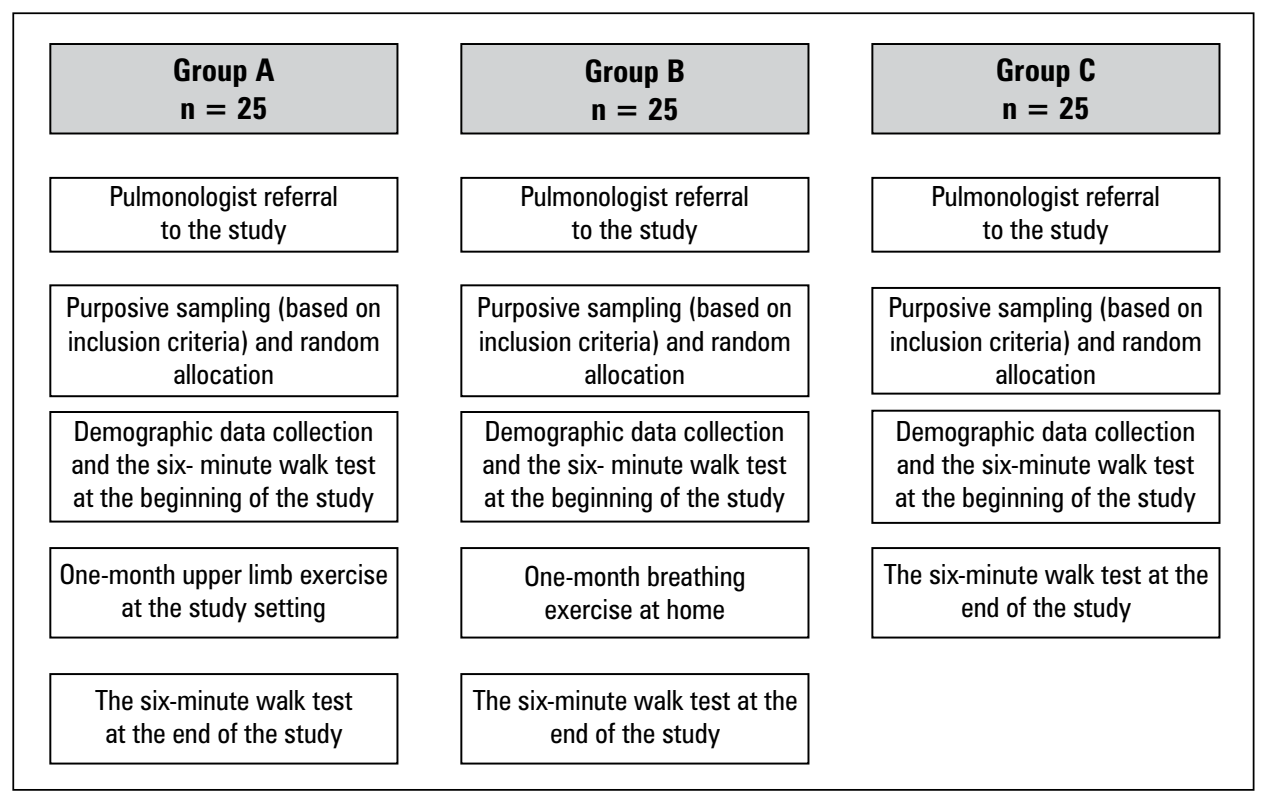

Figure 1. The flow diagram of participants in the study

\section{Table 1. Study participants characteristics}

\begin{tabular}{|c|c|c|c|c|c|c|}
\hline \multicolumn{2}{|c|}{$\begin{array}{l}\text { Groups } \\
\text { Characteristics }\end{array}$} & $\begin{array}{c}\text { Control } \\
\text { (Mean } \pm \text { SD) }\end{array}$ & $\begin{array}{l}\text { Upper limb exercise } \\
\quad \text { (Mean } \pm \text { SD) }\end{array}$ & $\begin{array}{l}\text { Breathing exercise } \\
\quad(\text { Mean } \pm \text { SD) }\end{array}$ & $\begin{array}{c}\text { Total } \\
\text { (Mean } \pm \text { SD) }\end{array}$ & p-value* \\
\hline \multicolumn{2}{|l|}{ Age (years) } & $64.2 \pm 13.4$ & $5 / 11 \pm 3 / 57$ & $8 / 11 \pm 16 / 61$ & $5 / 12 \pm 61$ & $p>0.05$ \\
\hline \multicolumn{2}{|c|}{ COPD duration (years) } & $4 / 7 \pm 4 / 8$ & $4 / 8 \pm 5 / 9$ & $4 / 10 \pm 11$ & $7 / 8 \pm 6 / 9$ & $p>0.05$ \\
\hline \multirow{2}{*}{\multicolumn{2}{|c|}{ Body mass index $\left(\mathrm{kg} / \mathrm{m}^{2}\right)$}} & $5 / 6 \pm 7 / 24$ & $6 / 4 \pm 5 / 25$ & $5 \pm 5 / 25$ & $42 / 5 \pm 29 / 25$ & $p>0.05$ \\
\hline & & $\mathrm{N}(\%)$ & $\mathrm{N}(\%)$ & $\mathrm{N}(\%)$ & $\mathrm{N}(\%)$ & $\mathrm{p}_{\text {-value }}{ }^{\wedge}$ \\
\hline \multirow[t]{2}{*}{ Gender } & Male & $18(72)$ & $18(72)$ & $19(76)$ & $55(73.3)$ & $p>0.05$ \\
\hline & Female & $7(28)$ & $7(28)$ & $6(24)$ & $20(26.6)$ & \\
\hline \multirow[t]{2}{*}{ Marital status } & Single & $1(4)$ & $0(0)$ & $0(0)$ & $1(1.3)$ & $p>0.05$ \\
\hline & Married & $24(96)$ & $25(100)$ & $25(100)$ & 74 (98.7) & \\
\hline \multirow{2}{*}{$\begin{array}{l}\text { Employment } \\
\text { status }\end{array}$} & Employed & $8(32)$ & $14(56)$ & $10(40)$ & $32(42.7)$ & $p>0.05$ \\
\hline & Retired & $17(68)$ & $11(44)$ & $15(60)$ & $43(57.3)$ & \\
\hline \multirow{5}{*}{$\begin{array}{l}\text { Educational } \\
\text { status }\end{array}$} & Illiterate & $11(44)$ & $4(16)$ & $9(36)$ & $24(32)$ & $p>0.05$ \\
\hline & Elementary & $6(24)$ & $10(40)$ & $10(40)$ & $26(34.7)$ & \\
\hline & Secondary & $6(24)$ & $3(12)$ & $4(16)$ & $13(17.4)$ & \\
\hline & Diploma & $2(8)$ & $3(12)$ & $2(8)$ & $7(9.3)$ & \\
\hline & University & $0(0)$ & $5(20)$ & $0(0)$ & $5(6.6)$ & \\
\hline \multirow{2}{*}{$\begin{array}{l}\text { Cigarette } \\
\text { smoking }\end{array}$} & No & $13(52)$ & $11(44)$ & $15(60)$ & $39(52)$ & $p>0.05$ \\
\hline & Yes & $12(48)$ & $14(56)$ & $10(40)$ & $36(48)$ & \\
\hline
\end{tabular}

*The results of the one-way analysis of variance; ${ }^{\wedge}$ The results of the Chi-square test

cational and employment status, and cigarette smoking.

The pretest and posttest mean values of walking distance in the control group were $366.5 \pm 44.1$ and $366.7 \pm 43.6$ meters, with no statistically significant difference $(\mathrm{p}>0.05)$.
However, the mean values of walking distance in the upper limb exercise and the breathing exercise groups significantly increased from respectively $389 . \pm 5.8$ and $355.3 \pm 47.9$ at pretest to $409.5 \pm 29.8$ and $376.9 \pm 37.0$ at posttest (p < 0.05; Table 2). 
Table 2. Comparison of the groups respecting walking distance

\begin{tabular}{lcccc}
\hline $\begin{array}{l}\text { Group } \\
\text { Time }\end{array}$ & $\begin{array}{c}\text { Control } \\
\text { (Mean } \pm \text { SD) }\end{array}$ & $\begin{array}{c}\text { Upper limb exercise } \\
\text { (Mean } \pm \text { SD) }\end{array}$ & $\begin{array}{c}\text { Breathing exercise } \\
\text { (Mean } \pm \text { SD) }\end{array}$ & p-value* $^{*}$ \\
\hline Before & $366.5 \pm 44.1$ & $389.8 \pm 5.8$ & $355.3 \pm 47.9$ & $\mathrm{p}>0.05$ \\
After & $366.7 \pm 43.4$ & $409.5 \pm 29.8$ & $376.9 \pm 37$ & $\mathrm{p}<0.05$ \\
$\mathrm{p}^{\text {-value }}{ }^{\wedge}$ & $\mathrm{p}>0.05$ & $\mathrm{p}<0.05$ & $\mathrm{p}<0.05$ & - \\
\hline${ }^{*}$ The results of the one-way analysis of variance; ${ }^{\wedge}$ The results of the paired-sample $t$ test & &
\end{tabular}

At pretest, the groups did not significantly differ from each other respecting the mean value of walking distance $(p>0.05)$. However, there was at least one statistically significant difference among the groups regarding the posttest mean value of walking distance $(p<0.05)$. Post hoc analysis indicated that walking distance in the upper lib exercise group was significantly greater than the breathing exercise and the control groups ( $p<0.05$ and $\mathrm{p}<0.05$, respectively), while walking distance in the breathing exercise group did not significantly differ from walking distance in the control group ( $p>0.05$; Table 2).

Also, after intervention, the mean walking distance in the patients of three groups was evaluated using post hoc test by LSD method. Results showed that there was a significant difference between the mean distance of the control group and the upper limb exercise group $(\mathrm{p}<0.05)$ and upper limb exercise and respiratory training groups $(\mathrm{p}<0.05)$.

\section{Discussion}

This study aimed to compare the effects of upper limb and breathing exercises on six-minute walking distance among patients with COPD. Findings revealed that both upper limb and breathing exercises had significant positive effects on walking distance. Moreover, findings showed that the results of upper limb exercise were significantly greater than the effects of breathing exercise.

In line with our findings, a former study showed that arm and shoulder exercises together with lower limb endurance exercises had positive consequences on exercise capacity among patients with COPD [24]. Another study reported that persons with COPD who performed inspiratory muscle and peripheral muscle exercises were able to walk significantly greater distances compared with their counterparts who solely performed peripheral muscle exercises [25]. Moreover, a study found that both aerobic and respiratory exercises were effective in significantly improving the results of six-minute walk test among patients with COPD [23]. Short-term endurance and strengthening exercises of the arm were also found to have positive effects on the exercise and the endurance capacities of the arm, while combined supported and unsupported arm exercises were more effective than unsupported exercises in improving arm endurance capacity [26]. Similarly, a study showed that respiratory muscle exercises had significant roles in improving treatment outcomes and the quality of life among patients with COPD [27].

The limitations of this study were related to the variations among participants respecting their walking clothes and shoes, lengthiness of the study intervention, and some patients' reluctance to participate in the study due to its lengthy course.

\section{Conclusion}

This study suggests that both upper limb and breathing exercises are effective in increasing walking distance among patients with COPD, though the effects of upper limb exercise are significantly greater than the results of breathing exercise. Therefore, upper limb exercise can be used as a safe, simple, and inexpensive technique for improving patient outcomes in pulmonary rehabilitation programs for persons with COPD.

\section{Conflict of interest}

The authors declare no conflict of interest.

\section{Acknowledgement}

We are truly thankful to patients who participated in the study and the authorities and the staff of Velayat hospital, Qazvin, Iran, who helped and supported us during the study.

\section{References:}

1. Morrow JD, Cho MH, Platig J, et al. Ensemble genomic analysis in human lung tissue identifies novel genes for chronic obstructive pulmonary disease. Hum Genomics. 2018; 12 (1): 1, doi: 10.1186/s40246-018-0132-z, indexed in Pubmed: 29335020 . 
2. Agustí A, Noguera A, Sauleda J, et al. Systemic effects of chronic obstructive pulmonary disease. European Respiratory Journal. 2003; 21 (2): 347-360, doi: 10.1183/09031936.03.00405703.

3. Elhoshy MS, Eshmawey HA, Tawab SS. Outcome of pulmonary rehabilitation in patients with COPD: Comparison between patients receiving exercise training and those receiving exercise training and CPAP. Egyptian Journal of Chest Diseases and Tuberculosis. 2017; 66 (4): 609-616, doi: 10.1016/j.ejcdt.2017.10.005.

4. Mohammed J, Derom E, Van Oosterwijck J, et al. Evidence for aerobic exercise training on the autonomic function in patients with chronic obstructive pulmonary disease (COPD): a systematic review. Physiotherapy. 2018; 104 (1): 36-45, doi: 10.1016/j.physio.2017.07.004, indexed in Pubmed: 28947079.

5. Salvi SS, Barnes PJ. Chronic obstructive pulmonary disease in non-smokers. Lancet. 2009; 374 (9691): 733-743, doi: 10.1016/ S0140-6736 (09)61303-9, indexed in Pubmed: 19716966.

6. Reilly J. Chronic obstructive pulmonary disease. The Brigham Intensive Review of Internal Medicine. 2014: 334-345, doi: 10.1093/med/9780199358274.003.0033.

7. McLean S, Hoogendoorn M, Hoogenveen RT, et al. Projecting the COPD population and costs in England and Scotland: 2011 to 2030. Sci Rep. 2016; 6: 31893, doi: 10.1038/srep31893, indexed in Pubmed: 27583987.

8. McKeough ZJ, Velloso M, Lima VP, et al. Upper limb exercise training for COPD. Cochrane Database Syst Rev. 2016; 11 CD011434, doi: 10.1002/14651858.CD011434.pub2, indexed in Pubmed: 27846347.

9. Vestbo J, Hurd SS, Agustí AG, et al. Global strategy for the diagnosis, management, and prevention of chronic obstructive pulmonary disease: GOLD executive summary. Am J Respir Crit Care Med. 2013; 187 (4): 347-365, doi: 10.1164/rccm 201204-0596PP, indexed in Pubmed: 22878278.

10. Butcher SJ, Pikaluk BJ, Chura RL, et al. Associations between isokinetic muscle strength, high-level functional performance, and physiological parameters in patients with chronic obstructive pulmonary disease. Int J Chron Obstruct Pulmon Dis. 2012; 7: 537-542, doi: 10.2147/COPD.S34170, indexed in Pubmed: 22973094.

11. Bourjeily G, Rochester C. Exercise training in chronic obstructive pulmonary disease. Clinics in Chest Medicine. 2000; 21 (4): 763-781, doi: 10.1016/s0272-5231 (05)70183-0.

12. Elmorsy A, Mansour A, Okasha A. Effect of upper limb, lower limb and combined training on exercise performance, quality of life and survival in COPD. Egyptian Journal of Chest Diseases and Tuberculosis. 2012; 61 (3): 89-93, doi: 10.1016/j. ejcdt.2012.10.008

13. Celli BR, Zuwallack RL, Pulmonary Re, Mason RJ, Ernst JD, King ET, Lazarus SC, Murray JF, Nadel JA. Textbook of Respiratory Medicine. Elsevier, 2016 : 1830-1821.

14. Pan L, Guo YZ, Yan JH, et al. Does upper extremity exercise improve dyspnea in patients with COPD? A meta-analysis. Respir Med. 2012; 106 (11): 1517-1525, doi: 10.1016/j. rmed.2012.08.002, indexed in Pubmed: 22902265.

15. Pan L, Guo Y, Yan J, et al. Does upper extremity exercise improve dyspnea in patients with COPD? A meta-analysis. Respiratory Medicine. 2012; 106 (11): 1517-1525, doi: 10.1016/j. rmed.2012.08.002.
16. Nyberg A, Saey D, Maltais F. Why and how limb muscle mass and function should be measured in patients with chronic obstructive pulmonary disease. Ann Am Thorac Soc. 2015; 12 (9): 1269-1277, doi: 10.1513/AnnalsATS.201505-278PS, indexed in Pubmed: 26208090.

17. Barreiro E, Gea J. Respiratory and limb muscle dysfunction in COPD. COPD. 2015; 12 (4): 413-426, doi: 10.3109/15412555.2014.974737, indexed in Pubmed: 25438125.

18. Houchen L, Steiner MC, Singh SJ. How sustainable is strength training in chronic obstructive pulmonary disease? Physiotherapy. 2009; 95 (1): 1-7, doi: 10.1016/j.physio.2008.09.004, indexed in Pubmed: 19627679.

19. Shah S, Nahar P, Vaidya S, et al. Upper limb muscle strength \& endurance in chronic obstructive pulmonary disease. Indian J Med Res. 2013; 138 (4): 492-496, indexed in Pubmed: 24434255.

20. Casaburi R. Activity promotion: a paradigm shift for chronic obstructive pulmonary disease therapeutics. Proc Am Thorac Soc. 2011; 8 (4): 334-337, doi: 10.1513/pats.201101-001RM, indexed in Pubmed: 21816989.

21. Waschki B, Kirsten A, Holz O, et al. Physical activity is the strongest predictor of all-cause mortality in patients with COPD: a prospective cohort study. Chest. 2011; 140 (2): 331-342, doi: 10.1378/chest.10-2521, indexed in Pubmed: 21273294.

22. Jokar Z, Mohammadi F, Khankeh HR, et al. Comparinghome -based pulmonary rehabilitation nursing on fatigue and quality of life in patients with COPD. Encyclopedia of Quality of Life and Well-Being Research. 2014: 4402-4402, doi: 10.1007/97894-007-0753-5_102785.

23. Boutwell A, Hwu S. Effective interventions to reduce rehospitalizations: a survey of the published evidence. Institute for Healthcare Improvement, Cambridge 2009.

24. Elkhateeb N, Elhadidi A, Masood H, et al. Pulmonary rehabilitation in chronic obstructive pulmonary disease. Egyptian Journal of Chest Diseases and Tuberculosis. 2015; 64 (2): 359369, doi: 10.1016/j.ejcdt.2015.03.001.

25. Naseer B, Al-Shenqiti A, Ali A, et al. Effect of a short term pulmonary rehabilitation programme on exercise capacity, pulmonary function and health related quality of life in patients with COPD. Journal of Taibah University Medical Sciences. 2017 12 (6): 471-476, doi: 10.1016/j.jtumed.2017.07.005.

26. Elmorsi A, Eldesoky M, Mohsen M, et al. Effect of inspiratory muscle training on exercise performance and quality of life in patients with chronic obstructive pulmonary disease. Egyptian Journal of Chest Diseases and Tuberculosis. 2016; 65 (1): 41-46, doi: 10.1016/j.ejcdt.2015.10.006.

27. Kathiresan G, Jeyaraman SK, Jaganathan J. Effect of upper extremity exercise in people with COPD. J Thorac Dis. 2010; 2 (4): 223-236, doi: 10.3978/j.issn.2072-1439.2010.11.4, indexed in Pubmed: 22263051.

28. Tout R, Tayara L, Halimi M. The effects of respiratory muscle training on improvement of the internal and external thoraco-pulmonary respiratory mechanism in COPD patients. Ann Phys Rehabil Med. 2013; 56 (3): 193-211, doi: 10.1016/j.rehab.2013.01.008, indexed in Pubmed: 23499539. 